\title{
Experts' views on digital competence: Commonalities and differences
}

Citation for published version (APA):

Janssen, J., Stoyanov, S., Ferrari, A., Punie, Y., Pannekeet, K., \& Sloep, P. (2013). Experts' views on digital competence: Commonalities and differences. Computers \& Education, 68, 473-481.

https://doi.org/10.1016/j.compedu.2013.06.008

DOI:

10.1016/j.compedu.2013.06.008

Document status and date:

Published: 01/10/2013

Document Version:

Early version, also known as pre-print

Document license:

CC BY-SA

Please check the document version of this publication:

- A submitted manuscript is the version of the article upon submission and before peer-review. There can be important differences between the submitted version and the official published version of record. People interested in the research are advised to contact the author for the final version of the publication, or visit the DOI to the publisher's website.

- The final author version and the galley proof are versions of the publication after peer review.

- The final published version features the final layout of the paper including the volume, issue and page numbers.

Link to publication

\section{General rights}

Copyright and moral rights for the publications made accessible in the public portal are retained by the authors and/or other copyright owners and it is a condition of accessing publications that users recognise and abide by the legal requirements associated with these rights.

- Users may download and print one copy of any publication from the public portal for the purpose of private study or research.

- You may not further distribute the material or use it for any profit-making activity or commercial gain

- You may freely distribute the URL identifying the publication in the public portal.

If the publication is distributed under the terms of Article 25fa of the Dutch Copyright Act, indicated by the "Taverne" license above, please follow below link for the End User Agreement:

https://www.ou.nl/taverne-agreement

Take down policy

If you believe that this document breaches copyright please contact us at:

pure-support@ou.nl

providing details and we will investigate your claim.

Downloaded from https://research.ou.nl/ on date: 26 Apr. 2023 


\title{
Experts' views on digital competence: commonalities and differences
}

\author{
José Janssen ${ }^{\mathrm{a}, *}$, Slavi Stoyanov ${ }^{\mathrm{a}}$, Anusca Ferrari ${ }^{\mathrm{b}}$, Yves Punie ${ }^{\mathrm{b}}$, Kees Pannekeet ${ }^{\mathrm{a}}$, Peter Sloep ${ }^{\mathrm{a}}$ \\ a. Open Universiteit Nederland, Centre for Learning Sciences and Technologies, Valkenburgerweg 177, PO Box 2960, \\ 6401 DL, Heerlen, The Netherlands \\ ${ }^{b .}$ Institute for Prospective Technological Studies (IPTS), European Commission, Joint Research Centre, Edificio Expo, \\ C/Inca Garcilaso 3, 41092 Seville, Spain
}

\begin{abstract}
Following earlier studies aimed at gaining a deeper understanding of digital competence through a review of literature and current digital competence frameworks, this paper focuses on experts' views on digital competence. It describes the results of a Delphi study investigating experts' ideas on what it means to be digitally competent today. The study involved two online consultations, one directed at gathering individual ideas and one directed at validating the aggregated mapping of digital competence, established through various qualitative and quantitative data analysis steps. The paper describes and discusses the final results from the Delphi study involving 95 experts from across Europe and beyond. Results indicate that digital competence is built up of knowledge, skills, and attitudes pertaining to twelve different areas. Besides, results show that several issues of debate can be identified when it comes to establishing the boundaries of digital competence.
\end{abstract}

Keywords: evaluation methodologies; lifelong learning; digital competence; concept mapping; delphi

\section{Introduction}

Without wanting to claim predominance of technology in the world today (Lanier, 2011), we do believe that few will dispute that digital technologies play an important role in present-day life. As do, by effect, the knowledge, skills, and attitudes that are required to deploy these technologies. Digital competence is one of the Eight Key Competences for Lifelong Learning as described by the European Parliament and the Council, and is defined as: the confident and critical use of Information Society Technology (IST) for work, leisure, and communication (European Community, 2007). This very brief definition of digital competence already reveals that digital competence relates to many aspects of life (work, leisure, communication) and is considered to stretch beyond mere know-how and technical skills, for it refers to confidence and a critical attitude as well.

What it means to be digitally competent in more practical terms though, is less evident. Some common ground exists at a general level in that competences can be described in terms of knowledge, skills, and attitudes, which may be hierarchically organised (Cheetham \& Chivers, 2005). However, with respect to digital competence, concrete elaborations vary depending on the context and the particular 'language' used, e.g. digital literacy, e-skills, information literacy, media literacy (Ala-Mutka, 2011), resulting in a 'jargon jungle' (Ferrari et al., 2012). An analysis of current frameworks for the development of digital competence identified 7 competence areas: Information Management, Collaboration, Communication \& Sharing, Creation of Content \& Knowledge, Ethics \& Responsibility, Evaluation \& Problem solving, and Technical operations (Ferrari et al., 2012). Although the frameworks tend to focus on technical operations, many are moving in a direction where they take into account higher order thinking skills in line with the 21-

\footnotetext{
* Corresponding author. Tel.: +31 45576 2847; fax: +31 576 2800. E-mail address: jose.janssen@ou.nl
} 
century skills perspective. In conclusion it can be said that these systematic reviews highlight the need to converge broad conceptual and narrow operational definitions on the one hand and digital and general competence on the other hand (Ala-Mutka, 2012; Ferrari et al., 2012).

All in all, current research and practice in the field of digital competence, reveals a scattered image, that fails to provide the transparency needed by teachers, employers, and citizens, i.e. all those who are responsible for digital competence development - be it their own or other people's. The transparency needed to make informed decisions, that is. In order to enhance understanding across the worlds of research, education, training, and policy a common language is needed. This will make it easier for citizens and employers to see what digital competence entails and how it is relevant to their jobs and lives more generally. To this end the present study brings together experts of digital competence representing a range of fields, to establish which knowledge, skills, and attitudes 'add up' to define digital competence. In addition the experts are asked to generate ideas on what it means to be digitally competent taking in mind various profiles: children, adolescents, senior citizens. The study was commissioned by the European Commission's Joint Research Centre (Institute of Prospective Technological Studies - IPTS) as part of the wider Digital Competence Project, launched in 2010 to foster development of a Digital Competence framework that can be validated at European level. We used the Delphi method to first collect ideas from the experts individually and then present the aggregated, collective, result back to them for further comments and refinement. Thus the method helps to establish both common ground and issues of debate. Section 2 describes the method in more detail. Section 3 describes the results from the experts' consultation. Finally, conclusions are drawn and implications discussed in Section 4.

\section{Method}

A Delphi survey, including both online and face-to-face consultations, was applied to facilitate a group of experts to first individually provide input to a mapping of digital competence and then validate (comment on) the collective result. This approach in fact combines advantages of the Delphi method, e.g. avoiding bandwagon effects (Linstone \& Turoff, 2002) and of the concept mapping approach, e.g. structured conceptualization and visualization (Trochim, 1989).

Clearly, idea generation requires open-ended questions. Asking open-ended questions via a questionnaire has several advantages over interviews, e.g. lower costs, and greater anonymity (Jackson \& Trochim, 2002). Both online and face-to-face consultations took place, leading to both qualitative and quantitative measures. We describe the subsequent steps of data collection and analysis in order to provide a clear outline.

\section{Idea generation via online questionnaire}

We asked the experts through an online questionnaire to generate as many ideas as possible completing the prompt: “A digitally competent person is someone who....”. Besides this general trigger statement there were three more prompts addressing specific profiles: a 7 year old child, a 14 year old adolescent, and a senior citizen. In addition we included some demographic questions (age, gender, professional experience etc.)

\section{Qualitative and quantitative data analysis}

\section{a. Data cleaning: selection of unique statements}

Ideas generated in the online brainstorm in reaction to the general prompt were 'cleaned', i.e. checked for identical statements, statements that contain more than one idea, and statements that are insufficiently clear. This resulted in an initial set of 134 statements. Throughout this process, carried out by two researchers on the base of mutual agreement, the intention was to maintain the original wording as much as possible to enhance a sense of ownership with participants. 


\section{b. Sorting and coding}

For analysing the text inputs of the participants we opted for Content Analysis rather than a Grounded Theory (Strauss \& Corbin, 1994) approach. Research suggests that Grounded Theory is more appropriate for longer narrative texts such as interview transcripts and journals. The sparse character of open-ended items makes Content Analysis the preferred method. There are two critical issues regarding the use of predefined coding schemas in Content Analysis. Firstly, these coding schemas may be interpreted differently by different coders and secondly, they may not be exhaustive causing the researcher to overlook important unexpected issues emerging in the data. For our study we have therefore adopted an explorative, bottom-up approach that builds upon the strength of classical Content Analysis, while trying to mitigate its weakness by not using researcher-driven predefined coding schemes. Instead, a selected group of participants ( $n=17)$ attending a dedicated digital competence workshop was asked to individually sort the statements into groups according to similarities and to name each group. In fact by sorting the statements into groups, the participants coded the statements themselves. Their individual coding schemes were aggregated applying hierarchical cluster analysis to quantitatively identify patterns in the data. This analysis resulted in an initial aggregated or 'collective' solution that organises the unique statements into 15 clusters (i.e. aspects of digital competence), which was then presented back to the workshop participants and discussed in small groups. Following these discussions both the number of statements and clusters was reduced, resulting in a description of digital competence through 14 clusters representing different aspects of digital competence.

\section{Feedback on initial solution from all experts via second online consultation}

Finally, all experts invited to the first round of the online consultation were addressed to take part in the second online consultation. The questionnaire of the second round served two purposes. Firstly, and fore mostly, the purpose was to validate the aggregated results from the first round. Secondly, the questionnaire aimed at gaining information on the relative importance of the knowledge, skills, and attitudes described in the statements, e.g. are they considered necessary for most people, some people or only a few?

\section{Adaptation following feedback from second online consultation: final solution}

Following the feedback from the second consultation round the initial solution was further adapted to result in the final solution described in the Results Section. Adaptations were made based on mutual agreement by three researchers.

\subsection{Participants}

The selection of a sample of experts typically involves techniques such as purposive sampling or criterion sampling (Hasson, Keeney, \& McKenna, 2000). Since the aim of this study is to develop a common language and understanding across different categories, representation (rather than representativeness) of a variety of views and opinions is essential. Therefore our target was to have a panel of experts reflecting a fair representation of sector groups (e.g. education \& training, research, IT-business, policy), expertise fields (e.g. primary to higher education, adult education, digital competence frameworks) and socio demographic variables (gender, age, country). To this end, a multifaceted purposive sampling strategy was adopted. This means that on top of identifying and selecting relevant experts within our own international networks, various search strategies were deployed to identify and select experts according to the sector or field they operate in (academic experts, experts involved in policy, education, IT-business, and digital competence frameworks). For academic experts, for instance, we screened editorial boards of journals as well as lists of presenters at conferences; for experts involved in policy or IT-business we searched websites of relevant companies and organisations etc. 
An initial list of 204 experts was created, about half of them provided by the Institute for Prospective Technological Studies and half by the researchers of the Open Universiteit Nederland. The list includes experts from all countries of the European Union, as well as from Norway, Switzerland, Israel, United States, and Australia. The first online questionnaire was completed by 79 experts (38\%). Responses were elicited by two reminders and by personally contacting experts whom we knew (either directly or indirectly). The second online questionnaire was completed by 57 experts (28\%). This group included 41 experts who had also provided input for the first round. The other 16 experts had been invited for the first round as well, but had not taken part at that stage. Comments on the final solution were given in various degrees: depending on the specific competence area, comments were made by 6 to 30 experts. Besides, 49 experts provided overall comments regarding the final solution. All in all, 95 experts (46\%) contributed to either the first or the second round, or both. This group includes experts from all countries represented in the original list of experts, except Poland, Switzerland and Luxembourg. Of the 79 experts responding to the demographic questions in the first consultation $35 \%$ is female and more than half is working as a researcher $(49 \%)$ or teacher/trainer (13\%). Views of policy makers, IT consultants, technology developers, representatives from industry are were less well represented. A vast majority (85\%) of participants has over 10 years experience in the field.

\section{Results and Discussion}

At the outset of the study there was some concern that results might focus on knowledge and skills as they are more concrete and thus more readily brought to mind in a brainstorm than attitudes. However, attitudes were abundantly represented in the ideas generated by the experts. Based on an analysis of the ideas generated in response to the general prompt ("A digitally competent person is someone who...") twelve digital competence areas have been identified. These twelve areas are summarized in Table 1. For a full description of each area and the statements describing the knowledge, skills, and attitudes pertaining to it we refer to the final report (ANON).

Table 1

Twelve digital competence areas

Digital competence area Description

A. General knowledge and functional skills

B. Use in everyday life

C. Specialized and advanced competence for work and creative expression

D. Technology mediated communication and collaboration

E. Information processing and management

F. Privacy and security
The digitally competent person knows the basics (terminology, navigation, functionality) of digital devices and can use them for elementary purposes.

The digitally competent person is able to integrate technologies into the activities of everyday life.

The digitally competent person is able to use ICT to express his/her creativity and to improve his/her professional performance.

The digitally competent person is able to connect, share, communicate, and collaborate with others effectively in digital environments.

The digitally competent person uses technology to improve his/her ability to gather, organise, analyse and judge the relevance and purpose of digital information.

The digitally competent person has the capacity to protect 
G. Legal and ethical aspects

H. Balanced attitude towards technology

I. Understanding and awareness of role of ICT in society

J. Learning about and with digital technologies

K. Informed decisions on appropriate digital technologies

L. Seamless use demonstrating self-efficacy
The digitally competent person behaves appropriately and in a socially responsible way in digital environments, demonstrating awareness and knowledge of legal and ethical aspects on the use of ICT and digital content.

The digitally competent person demonstrates an informed, open-minded, and balanced attitude towards Information Society and the use of digital technology. The digitally competent person is curious, aware of opportunities and new developments, and is comfortable to explore and exploit them.

The digitally competent person understands the broader context of use and development of information and communication technology.

The digitally competent person actively and constantly explores emerging technologies, integrates them in his/her environment and uses them for lifelong learning.

The digitally competent person is aware of most relevant or common technologies and is able to decide upon the most appropriate technology according to the purpose or need at hand.

The digitally competent person confidently and creatively applies digital technologies to increase personal and professional effectiveness and efficiency.

Analysis of the responses to subsequent prompts addressing specific profiles, revealed shifts of accents and examples, but no 'new' topics, not already covered by the response to the general prompt. A note of caution to make is that although these results can be considered a validated mapping of the collective views of experts in the field of digital competence, it should not be considered as representing consensus among the experts. Though many of the experts taking part in the second round indicated they agreed with the final mapping, and many of the comments and further suggestions made by them have been followed up, there were some more substantial differences between experts, that will be discussed shortly.

In addition to Table 1, Figure 1 illustrates how the various digital competence areas relate. It provides a schematic representation of the results and as such cannot completely reflect the richness of the results. However, it does reflect the kaleidoscopic nature of the ideas generated by experts, which comprised a mixture of competences, proficiency levels, purposes, technologies, and domains (application areas). Moreover, the figure illustrates how the various digital competence areas identified through the online consultation can be considered as 'building blocks'. 


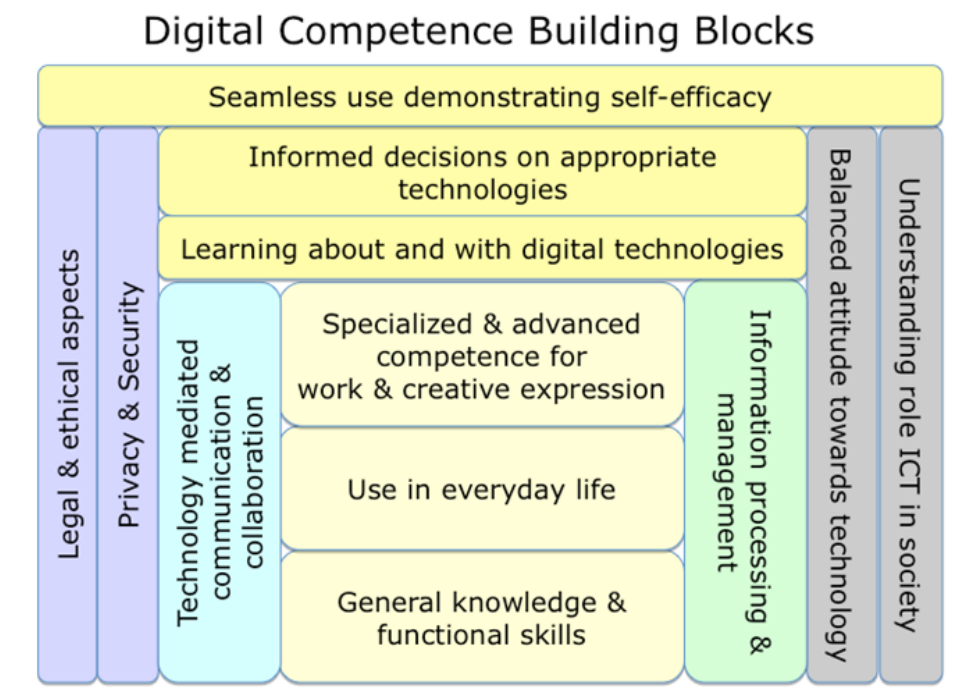

Fig. 1. Areas of digital competence: experts' collective view

Proficiency levels vary both within and between blocks. Most notably proficiency levels increase as we move up through the centre blocks. Eventually high proficiency levels are reflected in (self-directed) learning about and with technologies, informed decisions on appropriate technologies, and ultimately, smooth, seamless use of these technologies. 'Core' competences related to digital technology usage in every day life and at more advanced levels connected to creative expression and/or work are bolstered on the one hand by technology mediated communication and collaboration competences and competences relating to information processing and management on the other hand.

These digital competence areas involve direct, 'primary', use of digital technology, which must be embedded in or supported by other competences involving awareness and skills relating to the wider implications and impact of using digital technologies. These 'supportive' (but by no means less important) competences are: awareness of legal and ethical aspects, as well as privacy and security issues and the ability to act prudently in these matters on one side, and an understanding of the role of ICT in society together with a balanced attitude towards technology on the other side.

Finally, at an even higher level of reflection and integration, digital competence involves a number of competences which enable the digitally competent person to evaluate both his/her own digital competences and the surrounding digital environment in order to take appropriate decisions for self-development and enhancement of one's personal digital environment, ultimately resulting in a level of proficiency where the digitally competent person demonstrates self-efficacy and seamless use of digital technologies.

\subsection{Issues of debate}

The rating of statements lead experts to bring issues to the fore that can be characterised as 'open to debate', and which are interesting with a view on development of a framework of digital competence including indicators.

One issue involved the distinction between 'knowing and doing' or as one expert put it "separating use and ability". A number of statements described behaviour rather than ability, and we have solved this by rephrasing these statements to ability. For instance, the statement "Shares photo's/travel reports..." was rephrased to "Is able to share photos and travel reports via applications". However, there may be instances where this distinction can no longer be kept. In this respect consider for example the statement "Consults online sources as a matter of routine in all aspects of life". Rephrasing this statement to "Is able to..." would no longer be describing an attitude but a skill. Now some experts did indeed indicate that in their view the description of digital competence should be restricted to knowledge and skills, as they consider attitudes not to be part of digital competence. This view did not appear widespread, but still the example serves to 
illustrate that we cannot claim consensus. The picture of digital competence that emerged from the input of so many experts covers knowledge, skills, and attitudes as well as references to purpose, domain, and level. Some experts prefer a more confined approach to the definition of digital competence. We briefly discuss the most poignant issues of debate.

\subsubsection{General versus 'pure' digital competence}

There were a number of experts who advocated limiting the description to 'pure' digital competence and leaving out related but more general competences such as information processing skills:

"Information processing is [also] linked to cognitive processes and it is not necessarily related to digital competence”

"It should be considered what is "pure" digital competence and what is also deriving from other domains"

In our view a more confined approach to digital competence not only unnecessarily limits the scope of digital competence, but - more importantly - may prevent generation of important hypotheses, e.g. that digital technologies enhance cognitive processes. For example we may postulate that digital note taking or concept mapping significantly improve perception, memory or problem solving. Furthermore, the broader approach to digital competence has resulted in the identification of metacognition as an important component of digital competence, along with knowledge, skills, and attitudes:

"Can self monitor personal goals and can diagnose deficiencies of digital competence required for reaching these goals"

"Knows how to self-regulate his/her learning about digital technologies"

\subsubsection{Digital competence versus values and attitudes}

Some experts suggest making a strong distinction between competence and values/attitudes and to focus on digital competence only:

"Ethics and social values are not necessary part of the digital competences"

"Focus on skills/competences that can be taught, measured and assessed"

Nevertheless, our study identified attitudes as an important aspect of digital competence. Further support for inclusion of attitudes can be derived from the fact that the taxonomy of learning outcomes in the affective domain (Krathwohl, Bloom, \& Masia, 1973) receives as much recognition as the taxonomy of learning outcomes in the cognitive domain. A final point to make on this issue is that attitudes can be taught, measured and assessed: there is in fact a long tradition in teaching, learning, changing and measuring attitudes (Keller, 1987; Miller, 2005; Simonson \& Maushak, 2001).

\subsubsection{Digital competence versus digital preference}

An important recommendation made by experts is to draw a clear line between digital competence and personal preference, choice, or desire to use particular digital technologies.

"It's useful to know how to use social media but that doesn't mean that they have to use it. This is a personal choice. It is OK to not use Twitter, but it's a shame if someone does not know what it is or what it offers".

The fact that someone is capable of doing something does not necessarily imply that s/he likes it or wants to do it. Or the other way around: someone may be eager to use a particular digital technology without being sufficiently proficient to use it. Early adopters of a technology are not necessarily more proficient than later adopters. Preference and competence are two different types of cognitive constructs and research indicates that they do not correlate (Kirton, 2003). 
Finally, we highlight two points to be taken into account in the development of a framework considering recurring comments from experts. Firstly, in relation to various statements and the question to what extent the knowledge, skills, and/or attitude illustrated by them are needed, experts point out: "it depends", e.g. it depends on where you live (developed countries), what type of work you do, whether you want to... etc. Secondly, there is the notion of different levels of digital competence identified throughout experts' comments. Two different aspects of competence level are hinted at:

- Proficiency level (essential vs. advanced skills)

"For general digital competence the ability of gathering, assessing relevant information is the most important. Analyzing, structuring, classifying is perhaps already a higher level”

- Cognitive level (knowledge vs. understanding vs. application vs. problem solving)

"It is important to understand that they (major players such as Google, Facebook, and Twitter) may use personal data for commercial reasons. Know "how" they use data may be highly specialized...";

"Understands how" may be too much to look for - "Understands that" maybe a better phrase".

For both aspects, there is a suggestion that the lower levels are pre-conditions for the higher levels.

\section{Conclusions}

The Delphi study described in this paper 'brought together' 95 experts coming from a range of fields in order to establish common ground concerning the knowledge, skills, and attitudes constituting digital competence. Our prior expectation (and concern) was that the ideas generated in the brainstorming would focus on knowledge and skill aspects of digital competence. Much to our surprise attitudes had a relevant part in the input.

Qualitative research often requires a balancing act between academic (and common sense) values of parsimony and conciseness on the one hand and doing justice to the rich variety of ideas and nuances emerging from the data. Though this in itself does not constitute a problem, it is good to be aware that validating the results of the first round by means of a second consultation and subsequently presenting a 'final', 'collective' solution, does not mean that the final result reflects consensus. Nuances were made, and differences identified regarding: inclusion of skills considered to belong to another domain (e.g. information processing skills), inclusion of values and attitudes, distinguishing between competence and preference, competence levels (both proficiency levels and cognitive levels).

Results indicate that experts see digital competence as a conglomerate of knowledge, skills, and attitudes connected to various purposes (communication, creative expression, information management, personal development, etc.), domains (daily life, work, privacy \& security, legal aspects), and levels. The twelve areas of digital competence identified in this study are highly complementary. Possessing elementary skills is one thing, applying them in everyday life is something else, as is expanding them to more advanced areas. Digital Competence clearly involves more than knowing how to use devices and applications - which is intricately connected with skills to communicate using ICT as well as information management skills. Besides, sensible and healthy use of ICT requires particular knowledge and attitudes regarding legal and ethical aspects, and privacy and security, as well as an understanding of the role of ICT in society and a balanced attitude towards technology. Needless to say, that various levels of proficiency can be identified for each of these areas. Finally, dictated by the nature of information and communication technologies, i.e. their rapid development, digital competence requires the ability to learn about and with digital technologies, to choose the right technology and to do so in confidence.

A common, in the sense of 'unanimous' understanding of digital competence may not be feasible, but this study has contributed to an understanding of the differences, which can then be used for instance to create a framework which may include a 'restricted' and a 'broad' conceptualisation of digital competence. 


\section{Acknowledgements}

Delphi studies rely heavily on the input of those taking part in it. We are grateful to the varied and very rich input we received throughout the study and feel much indebted to all 95 experts taking part in it. The work presented in this article was commissioned by the Institute for Prospective Technological Studies (IPTS) of the European Commission's Joint Research Centre (Project no. IPTS-2011-J04-46-NC). The views expressed here are purely those of the authors and may not in any circumstances be regarded as stating an official position of the European Commission.

\section{References}

Ala-Mutka, K. (2011). Mapping Digital Competence: Towards a Conceptual Understanding. Seville: JRC IPTS. Retrieved from http://ipts.jrc.ec.europa.eu/publications/pub.cfm?id-5099

Cheetham, G., \& Chivers, G. (2005). Professions, Competence And Informal Learning. Cheltenham: Edward Elgar Publishing.

European Community. (2007). Key Competences for Lifelong Learning - A European Framework. Luxembourg.

Ferrari, A. (2012). Digital Competence in Praxis: an Analysis of Frameworks (pp. 1-91). Seville: JRC IPTS. Retrieved from http://is.jrc.ec.europa.eu/pages/EAP/documents/FinalCSReport_PDFPARAWEB.pdf

Ferrari, A., Punie, Y., \& Redecker, C. (2012). Understanding Digital Competence in the 21st Century: An Analysis of Current Frameworks. In A. Ravenscrotft, S. Lindstaedt, C. D. Kloos, \& D. Hernández-Leo (Eds.), 21st Century Learning for 21st Century Skills (pp. 79-92). Berlin Heidelberg: Springer.

Hasson, F., Keeney, S., \& McKenna, H. (2000). Research guidelines for the Delphi survey technique. Journal of Advanced Nursing, 32(4), 1008-1015.

Jackson, K., \& Trochim, W. (2002). Concept Mapping as an alternative approach for the analysis of openended survey responses. Organizational Research Methods, 5(4), 307-336.

Keller, J. M. (1987). Development and use of the ARCS model of instructional design. Journal of Instructional Development, 10(3), 2-10.

Kirton, M. J. (2003). Adaptation - Innovation in the context of diversity and change. London: Routledge.

Krathwohl, D. R., Bloom, B. S., \& Masia, B. B. (1973). Taxonomy of Educational Objectives, the Classification of Educational Goals. Handbook II: Affective Domain. New York: David McKay Co., Inc.

Lanier, J. (2011). You Are Not a Gadget. London: Penguin Books.

Linstone, H. A., \& Turoff, M. (2002). Introduction. In H. A. Linstone \& M. Turoff (Eds.), The Delphi Method Techniques and Applications (pp. 3-12). Retrieved from http://is.njit.edu/pubs/delphibook/delphibook.pdf

Miller, M. (2005). Teaching and Learning in Affective Domain. In M. Orey (Ed.), Emerging perspectives on learning, teaching, and technology. Association for Educational Communications and Technology. Retrieved from http://projects.coe.uga.edu/epltt/index.php?title=Main_Page

Simonson, M., \& Maushak, N. (2001). Instructional technology and attitude change. In D. Jonassen (Ed.), Handbook of research for educational communications and technology. (pp. 984-1016). Mahway, NJ: Lawrence Erlbaum Associates.

Strauss, A., \& Corbin, J. (1994). Grounded Theory Methodology - An Overview. In N. K. Denzin \& Y. S. Lincoln (Eds.), Handbook of Qualitative Research (pp. 273-285). Thousand Oaks: Sage Publications.

Trochim, William, M. K. (1989). An introduction to concept mapping for planning and evaluation. Evaluation and Program Planning, 12, 1-16. 